\title{
Studi Eksperimen Perpindahan Panas Konveksi Paksa Pada Berkas Pin Fin Berpenampang Circular dengan Susunan Aligned
}

\author{
Linda Wijiati dan Budi Utomo Kukuh Widodo \\ Departemen Teknik Mesin, Fakultas Teknologi Industri \\ Institut Teknologi Sepuluh Nopember (ITS) 60111 Indonesia \\ e-mail: buditem@me.its.ac.id
}

\begin{abstract}
Abstrak-Fin digunakan untuk meningkatkan perpindahan panas dengan menambah luasan atau area perpindahan panas yang disebut extended surface. Salah satu media untuk mendemonstrasikan fenomena perpindahan panas pada fin adalah dengan melakukan studi eksperimen. Studi eksperimen ini digunakan untuk mengetahui pengaruh diameter fin dan kecepatan udara terhadap perpindahan panas konveksi serta distribusi temperature di sepanjang fin. Pengujian dilakukan dengan menggunakan circular pin fin yang berjumlah 16 dengan diameter $10 \mathrm{~mm}$ dan $16 \mathrm{~mm}$ serta panjang $70 \mathrm{~mm}$. Pin fin diletakkan di dalam rectangular duct dan disusun secara aligned dengan $S_{T}=20 \mathrm{~mm}$ dan $S_{L}=20 \mathrm{~mm}$. Electric plate heater diletakkan pada base plate sebagai sumber panas yang dikontrol menggunakan thermocontrol yaitu pada $\mathrm{T}=50^{\circ} \mathrm{C}$ dan $\mathrm{T}=70^{\circ} \mathrm{C}$. Kecepatan aliran udara divariasikan dengan menggunakan variasi air inlet pada centrifugal blower. Setelah itu dilakukan pembacaan temperature masing-masing pada 1 titik pada base plate, $T_{\text {out }}$ dan 24 titik pada circular pin fin. Pengukuran temperature dilakukan dengan thermocouple dan akuisisi data yang terintegrassi pada computer. Hasil penelitian menunjukkan distribusi temperature menurun sepanjang pin fin. Reynolds number terbesar terjadi pada $v=4.20 \mathrm{~m} / \mathrm{s}$. Pada kecepatan yang sama, fin 10 mm mempunyai koefisien konveksi yang lebih besar daripada fin $16 \mathrm{~mm}$.
\end{abstract}

Kata Kunci-Circular Pin Fin, Extended Surface, Konveksi Paksa, Rectangular Duct, Susunan Aligned

\section{PENDAHULUAN}

GIRIP merupakan salah satu aplikasi dari ilmu $\checkmark$ perpindahan panas yang berfungsi untuk meningkatkan luasan perpindahan panas. Peningkatan luas perpindahan panas dapat menyebabkan meningkatnya laju perpindahan panas. Aplikasi sirip pin dapat dilihat pada heat exchanger dan heat sink.

Sirip atau pin fin dipengaruhi juga oleh konduktivitas termal material. Pemanfaatan fin menjadi lebih maksimal apabila material dari pin fin memiliki konduktivitas termal yang baik. Pada rentang nilai Reynolds number yang sama, laju perpindahan panas terbesar dicapai oleh aluminium daripada tembaga dengan diameter pin fin yang sama [1].

Perpindahan panas dipengaruhi oleh bentuk geometri, kondisi aliran dan properties fluida. Peningkatan kecepatan aliran udara menyebabkan peningkatan Reynolds number dan Nusselt number. Peningkatan Nusselt number dapat menyebabkan meningkatnya koefisien perpindahan panas konveksi atau $h$. Oleh karena itu, laju perpindahan panas fin semakin besar dengan naiknya kecepatan udara [2].

Susunan pin fin memengaruhi besar perpindahan panas. Susunan staggered menghasilkan besar perpindahan panas yang lebih baik daripada susunan aligned. Namun, penurunan tekanan pada susunan staggered lebih besar daripada susunan aligned.

Studi ini membahas studi eksperimen tentang perpindahan panas konveksi paksa melalui pin fin berpenampang circular dengan susunan aligned.

\section{URAIAN PENELITIAN}

Perpindahan panas konveksi merupakan perpindahan panas yang terjadi akibat adanya perbedaan temperatur yang menyebabkan gerakan acak antarmolekul dan bulk motion of fluid. Semakin cepat pergerakan fluida, maka akan semakin besar pula laju perpindahan panas konveksi yang terjadi. Namun, apabila fluida tidak bergerak atau stationary maka mekanisme perpindahan panas yang terjadi adalah konduksi.

Konveksi terjadi akibat adanya pergerakan fluida, oleh karena itu konveksi dapat dibedakan menjadi 2, yaitu konveksi alami dan konveksi paksa. Konveksi alami (konveksi bebas) terjadi karena fluida bergerak secara alamiah di mana pergerakan fluida tersebut lebih disebabkan oleh perbedaan massa jenis fluida akibat adanya variasi suhu pada fluida tersebut. Konveksi paksa terjadi karena bergeraknya fluida bukan karena faktor alamiah.

Perpindahan panas dalam aliran yang melintasi sirip sangat penting dalam aplikasi heat exchanger (penukar panas), peralatan elektronik dan motor listrik. Aliran fluida melintasi sirip pin secara melintang (cross flow). Pin pada baris pertama bertindak sebagai pembangkit turbulensi yang meningkatkan perpindahan panas konveksi untuk sirip selanjutnya. Oleh karena itu, koefisien perpindahan panas untuk sirip pin pada baris pertama kira-kira sama dengan single fin dalam aliran melintang (cross flow). Untuk baris selanjutnya, kondisi aliran sangat bergantung pada susunan sirip. Sirip disusun secara sebaris (aligned) atau secara selang-seling (staggered) yang ditandai dengan adanya longitudinal dan transversal pitches seperti pada Gambar 1.

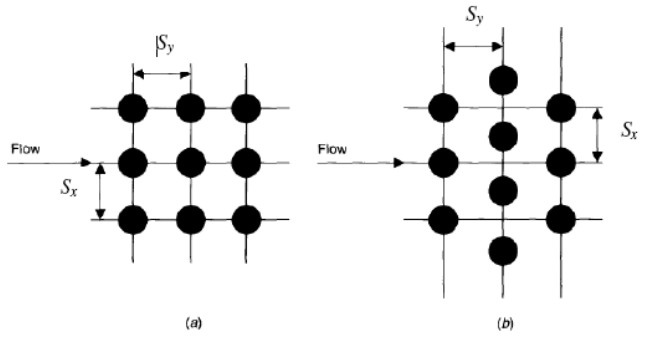

Gambar 1. Susunan pin fin (a) aligned (b) staggered

Dalam rancang bangun perangkat ini, digunakan 16 buah circular pin fin berdiameter $10 \mathrm{~mm}$ dan $16 \mathrm{~mm}$ dengan tinggi $70 \mathrm{~mm}$. Circular pin fin terbuat dari aluminium alloy 6061 
disusun secara aligned yang diletakkan pada base plate berdimensi $100 \mathrm{~mm}$ x $100 \mathrm{~mm}$ dan dipasangkan di dalam rectangular duct. Rectangular duct yang digunakan memiliki geometri $159 \mathrm{~mm}$ x $90 \mathrm{~mm}$ x $716 \mathrm{~mm}$. Circular pin fin memiliki nilai $S_{T}=20 \mathrm{~mm}$ dan $S_{L}=20 \mathrm{~mm}$.

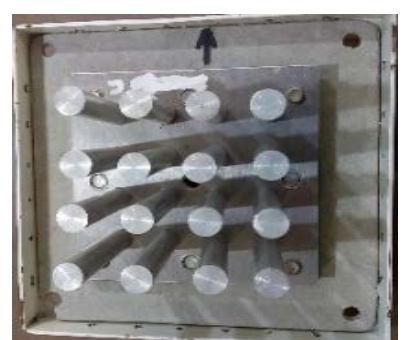

(a)

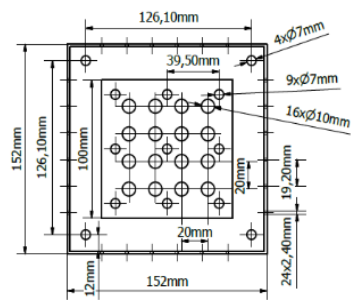

(b)
Gambar 2. Circular pin fin (a) tampak atas (b) tampak atas dengan dimensi

Centrifugal blower sebagai alat untuk mengalirkan udara ke dalam rectangular duct dan terdapat variasi kecepatan udara. Kecepatan udara yang digunakan adalah $2.46 \mathrm{~m} / \mathrm{s}, 3.65$ $\mathrm{m} / \mathrm{s}, 3.96 \mathrm{~m} / \mathrm{s}$ dan $4.20 \mathrm{~m} / \mathrm{s}$.

Berkas pin fin dipanasi dengan constant heat flux, yaitu menggunakan electric plate heater yang diletakkan di base plate sebagai sumber panas dengan daya 150 Watt. Pemanasan pada circular pin fin dilakukan dengan menjaga agar temperature electric plate heater tetap konstan sebesar $50^{\circ} \mathrm{C}$ dan $70^{\circ} \mathrm{C}$. Kemudian dilakukan pembacaan data temperature di 26 titik, yaitu 24 titik pada circular pin fin, 1 titik pada base plate serta pada $T_{\text {out }}$. Pengukuran temperature menggunakan thermocouple tipe $\mathrm{K}$ sebagai sensor temperature. Gambar skema alat uji dapat dilihat pada Gambar 3.

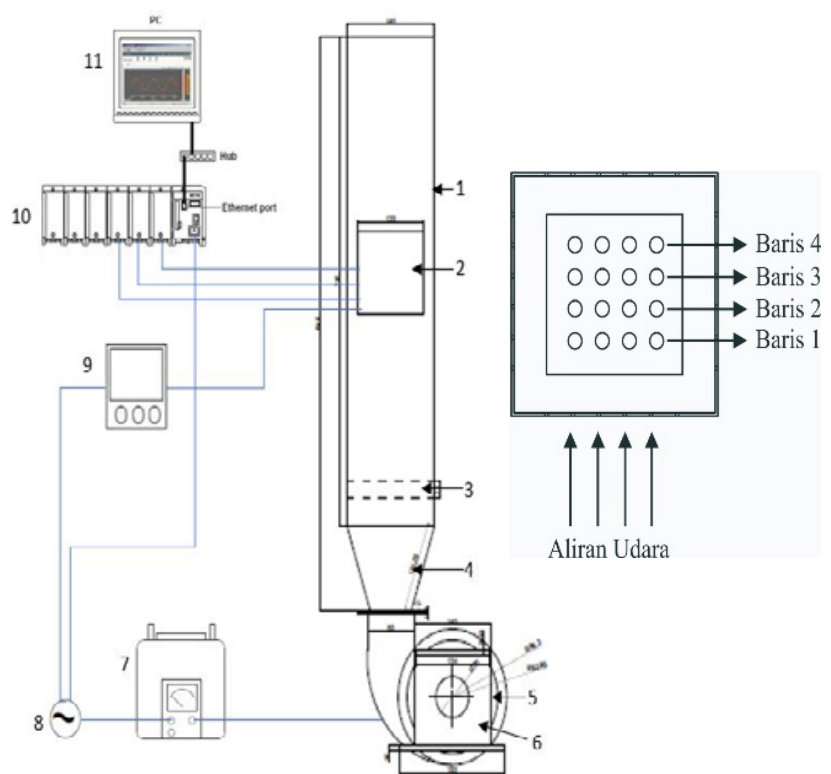

Gambar 3. Skema alat uji dan aliran udara saat melewati benda uji

\section{Keterangan:}

$1=$ Rectangular duct

2 = Base Plate and plate electrical heater

$3=$ Honeycomb

$4=$ Diffuser

5 = Centrifugal Blower

$6=$ Air inlet

7 = Voltage regulator

8 = Power supply

$9=$ Thermocontrol Digital

$10=$ DAQ MX 100

$11=\mathrm{PC}$
Eksperimen dilakukan untuk mendemonstrasikan perpindahan panas konveksi paksa melalui circular pin fin dengan variasi kecepatan udara dan diameter sirip pin. Dengan variasi kecepatan udara dan diameter sirip pin dapat diketahui bagiamana pengaruhnya terhadap laju perpindahan panas konveksi paksa pada sirip, serta mengetahui distribusi temperatur sepanjang sirip. Pemasangan kabel thermocouple diletakkan pada base plate dan fin, yaitu pada $x=0, x=1 / 3 L$, $x=2 / 3 L$ dan $x=L$. Pengambilan data temperatur dilakukan dengan perangkat akuisisi data DAQ MX 100 yang dapat ditampilkan dalam bentuk microsoft excel.

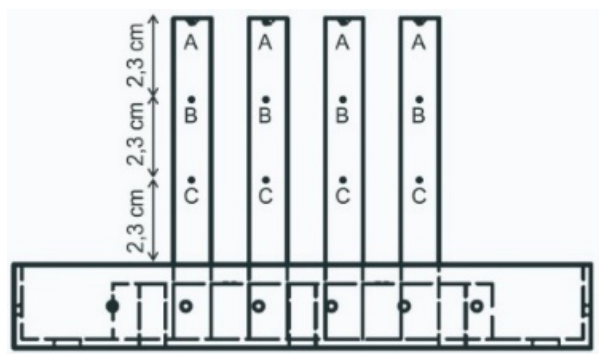

Gambar 4. Pengukuran temperature pada pin fin

Perhitungan perpindahan panas pada penelitian ini dapat menggunakan heat balance dalam kondisi steady state seperti pada Gambar 5.

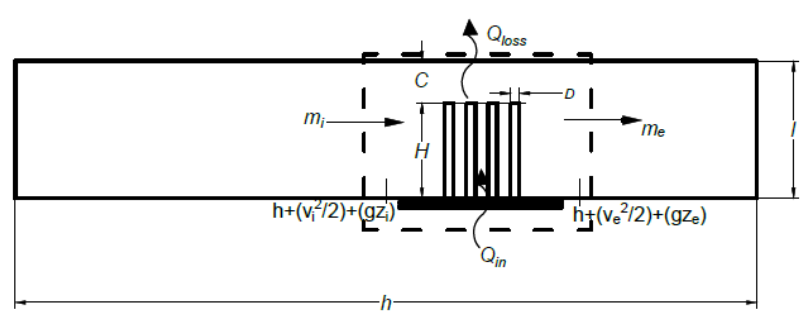

Gambar 5. Control volume analisis heat balance

Keterangan:

$$
\begin{aligned}
C & =\text { clearance } & & =22 \mathrm{~mm} \\
H & =\text { tinggi/panjang fin } & & =70 \mathrm{~mm} \\
D & =\text { diameter fin } & & =10 \mathrm{~mm} \text { dan } 16 \mathrm{~mm} \\
t & =\text { tebal base plate } & & =8 \mathrm{~mm} \\
W & =L=\text { lebar base plate } & & =100 \mathrm{~mm} \\
p & =\text { panjang cross section } & & =159 \mathrm{~mm} \\
l & =\text { lebar cross section } & & =90 \mathrm{~mm} \\
h & =\text { tinggi rectangular duct } & & =716 \mathrm{~mm}
\end{aligned}
$$

Perhitungan heat balance pada skema Gambar 5 dapat dirumuskan sebagai:

$$
\begin{aligned}
\frac{d E_{c v}}{d t}= & \dot{Q}_{i n}-\dot{W}_{c v}+\dot{m}_{i}\left(h_{i}+\frac{v_{i}^{2}}{2}+g z_{i}\right)+ \\
& \dot{m}_{e}\left(h_{e}+\frac{V_{e}^{2}}{2}+g z_{e}\right)
\end{aligned}
$$

dengan $Q_{\text {in }}$ merupakan panas dari heater. Berdasarkan mass balance, maka mass flow rate inlet sama dengan massflow rate exit. Heat loss dari system terjadi karena radiasi dari permukaan dan konduksi melalui dinding ke atmosfer.

$$
\frac{d E_{c v}}{d t}=Q_{c v}-W_{c v}+\dot{m}\left(h+\frac{V^{2}}{2}+g z\right)
$$

dengan asumsi yaitu kondisi steady state, energi potensial dan energi kinetik diabaikan, serta tidak ada kerja yang terjadi, sehingga Persamaan 2 menjadi:

$$
Q_{c v}=\dot{m}(h)
$$

dengan entalpi $h=c_{p} \Delta T$, maka Persamaan 3 menjadi:

$$
Q_{c v}=\dot{m} c_{p} \Delta T
$$

dengan:

$$
\dot{m}=\rho A_{f f} v
$$


Free flow area $\left(A_{f f}\right)$ merupakan area yang dilewati oleh aliran udara, $A_{f f}$ dirumuskan sebagai berikut:

$$
A_{f f}=(p l)-\left(N_{x} H_{f i n} D_{f i n}\right)
$$

keterangan:

$$
\begin{array}{ll}
\dot{m} & =\text { laju aliran massa udara }(\mathrm{kg} / \mathrm{s}) \\
c_{p} & =\text { panas jenis udara }(\mathrm{J} / \mathrm{kg} . \mathrm{K}) \\
T_{\text {in }} & =\text { temperatur inlet aliran udara }(\mathrm{K}) \\
T_{\text {out }} & =\text { temperatur outlet aliran udara }(\mathrm{K}) \\
v & =\text { kecepatan aliran udara }(\mathrm{m} / \mathrm{s} \\
\rho & =\text { massa jenis udara }\left(\mathrm{kg} / \mathrm{m}^{3}\right) \\
A_{f f} & =\text { free flow area }\left(\mathrm{m}^{2}\right) \\
N_{x} & =\text { jumlah pin fin } \text { arah transversal }
\end{array}
$$

Perpindahan panas secara konveksi dari permukaan pin fin dan base plate dapat dirumuskan sebagai berikut:

$$
Q_{\text {conv }}=\bar{h} A_{s}\left[T_{b}-\frac{T_{\text {in }}+T_{\text {out }}}{2}\right]
$$

dengan

$$
A_{s}=(W L)+\left(\pi D_{f i n} H_{f i n} N_{x y}\right)
$$

keterangan:

$$
\begin{array}{lll}
L & =\text { lebar base plate } & =100 \mathrm{~mm} \\
H_{\text {fin }} & =\text { tinggi pin fin } & =70 \mathrm{~mm} \\
N_{x y} & =\text { jumlah pin fin } & =16 \\
D & =\text { diameter of fin } & =10 \mathrm{~mm} \text { dan } 16 \mathrm{~mm} \\
\mathrm{~W} & =\text { wide of base plate } & =100 \mathrm{~mm}
\end{array}
$$

Koefisien perpindahan panas konveksi rata-rata dapat dihitung melalui subtitusi Persamaan 4 dan Persamaan 7, sehingga diperoleh nilai koefisien rata-rata sebagai berikut:

$$
\bar{h}=\frac{\dot{m} c_{p}\left(T_{\text {in }}-T_{\text {out }}\right)}{A_{s}\left[\bar{T}_{s}-\left(\frac{T_{\text {in }}-T_{\text {out }}}{2}\right)\right]}
$$

\section{HASIL DAN PEMBAHASAN}

A. Distribusi temperature pada pin fin di setiap variasi adalah sebagai berikut:

Gambar 6 merupakan gambar distribusi temperature permukaan pin fin berdiameter $10 \mathrm{~mm}$ dan $16 \mathrm{~mm}$ dengan set point $50^{\circ} \mathrm{C}$ dan $70^{\circ} \mathrm{C}$ pada baris pertama. Baris pertama terdiri dari 4 pin fin dengan 2 pin fin terukur yaitu pin fin 7 dan 8. Dari grafik dapat diketahui bahwa masing-masing pin fin mempunyai trendline grafik yang sama. Trendline grafik mengalami penurunan temperature di sepanjang pin fin. Temperature tertinggi terjadi pada $\mathrm{x}=0$ dan temperature terendah pada posisi $\mathrm{x}=70 \mathrm{~mm}$. Pin fin 8 memiliki temperature yang lebih tinggi daripada pin fin 7.

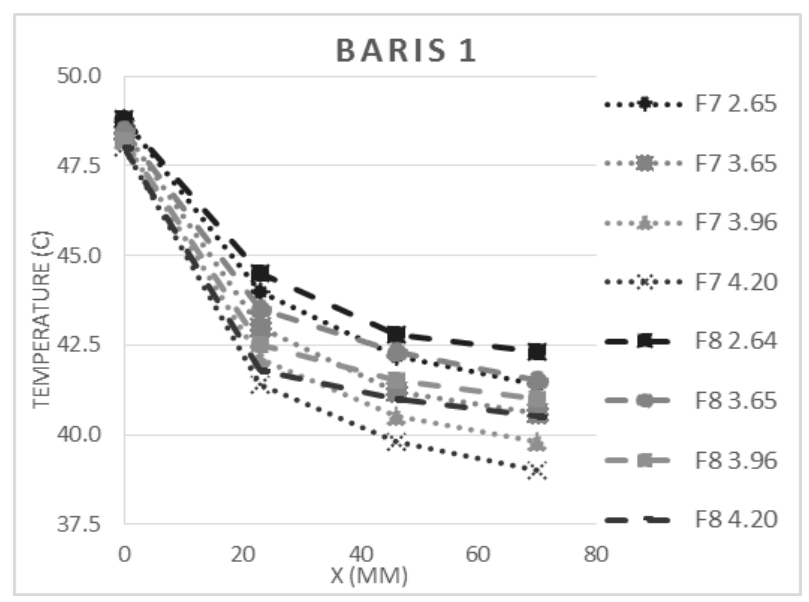

(a)

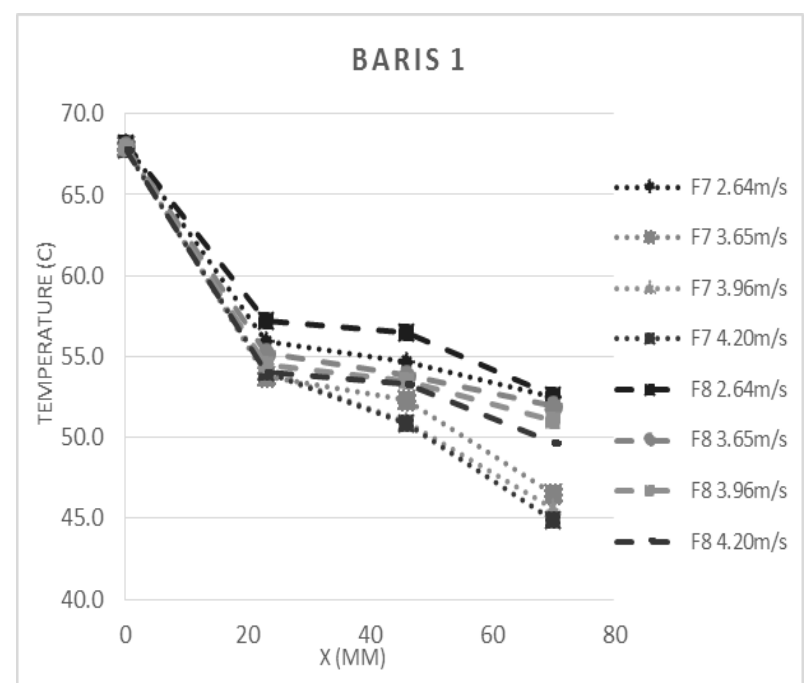

(b)

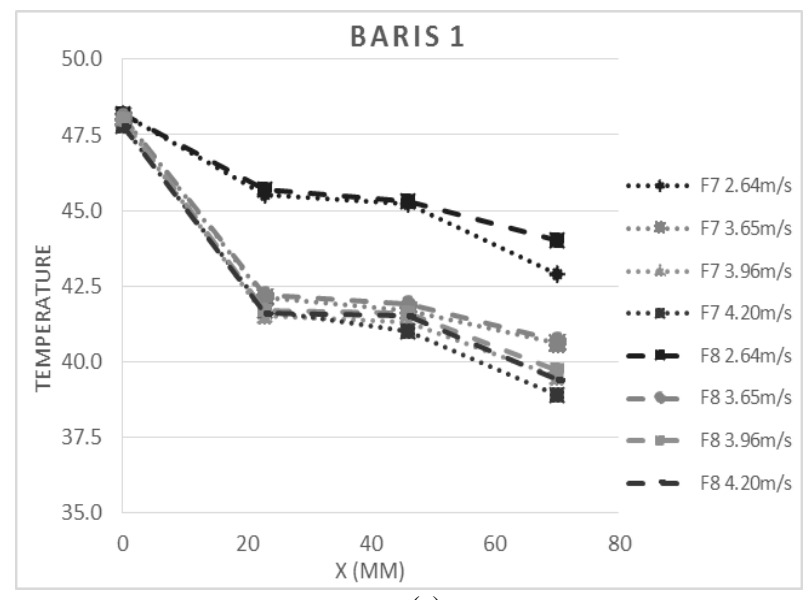

(c)

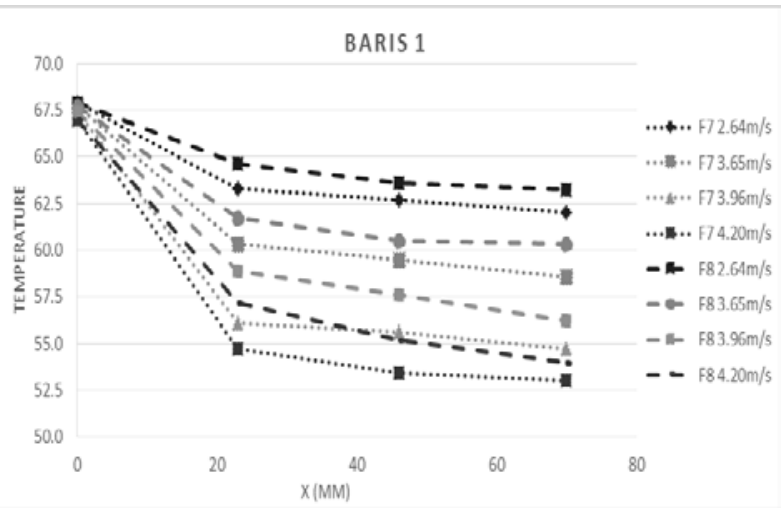

(d)

Gambar 6. Distribusi temperature pin fin pada baris pertama (a) pin fin 10 $\mathrm{mm}$ set point $50^{\circ} \mathrm{C}$ (b) pin fin $10 \mathrm{~mm}$ set point $70^{\circ} \mathrm{C}$ (c) pin fin $16 \mathrm{~mm}$ set point $50^{\circ} \mathrm{C}$ (d) pin fin $16 \mathrm{~mm}$ set point $70^{\circ} \mathrm{C}$

Gambar 7 merupakan grafik distribusi temperature permukaan pin fin dengan diameter $10 \mathrm{~mm}$ dan $16 \mathrm{~mm}$ dengan set point $50^{\circ} \mathrm{C}$ dan $70^{\circ} \mathrm{C}$ pada baris kedua. Baris kedua terdiri dari 4 pin fin dengan 2 pin fin terukur yaitu pin fin 5 dan 6. Dari grafik dapat diketahui bahwa masing-masing pin fin mempunyai trendline grafik yang sama. Trendline grafik mengalami penurunan temperature di sepanjang pin fin. Temperature tertinggi terjadi pada $\mathrm{x}=0$ dan temperature terendah pada posisi $\mathrm{x}=70 \mathrm{~mm}$. Pin fin 5 memiliki temperature yang lebih tinggi daripada pin fin 6 . 


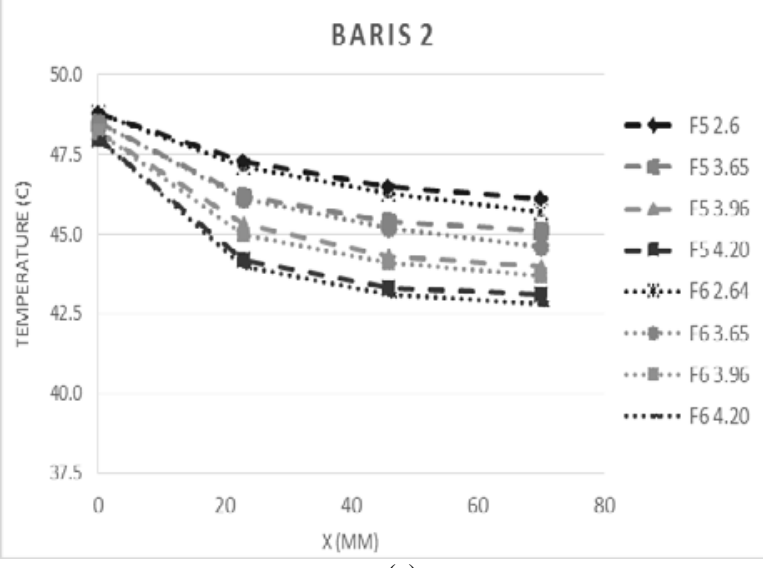

(a)

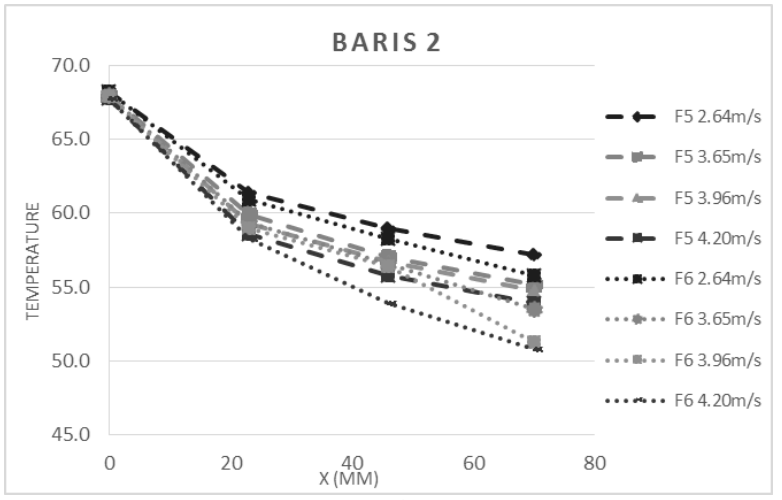

(b)

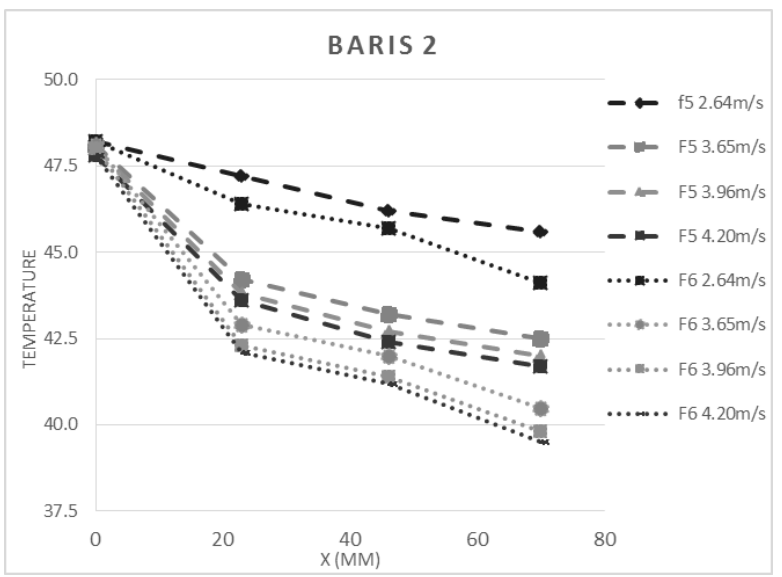

(c)

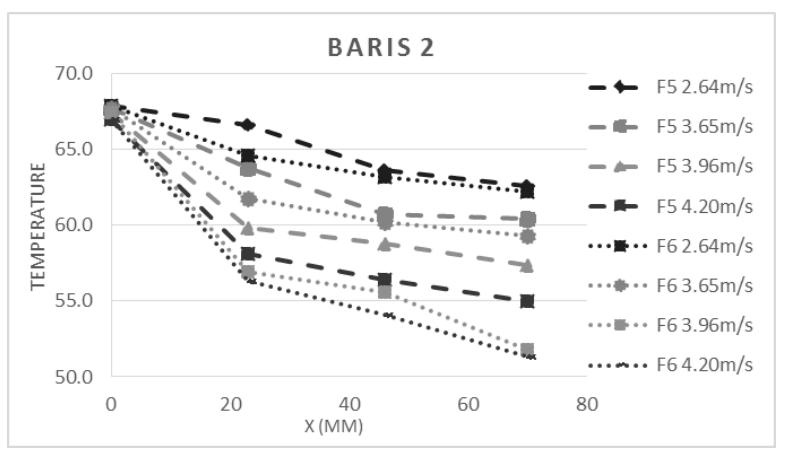

(d)

Gambar 7. Distribusi temperature pin fin pada baris ketiga (a) pin fin $10 \mathrm{~mm}$ set point $50^{\circ} \mathrm{C}$ (b) pin fin $10 \mathrm{~mm}$ set point $70^{\circ} \mathrm{C}$ (c) pin fin $16 \mathrm{~mm}$ set point $50^{\circ} \mathrm{C}$ (d) pin fin $16 \mathrm{~mm}$ set point $70^{\circ} \mathrm{C}$

Gambar 8 merupakan grafik distribusi temperature permukaan pin fin dengan diameter $10 \mathrm{~mm}$ dan $16 \mathrm{~mm}$ dengan set point $50^{\circ} \mathrm{C}$ dan $70^{\circ} \mathrm{C}$ pada baris ketiga. Baris ketiga terdiri dari 4 pin fin dengan 2 pin fin terukur yaitu pin fin 3 dan 4. Dari grafik dapat diketahui bahwa masing-masing pin fin mempunyai trendline grafik yang sama. Trendline grafik mengalami penurunan temperature di sepanjang pin fin. Temperature tertinggi terjadi pada $\mathrm{x}=0$ dan temperature terendah pada posisi $\mathrm{x}=70 \mathrm{~mm}$. Pin fin 4 memiliki temperature yang lebih tinggi daripada pin fin 3.

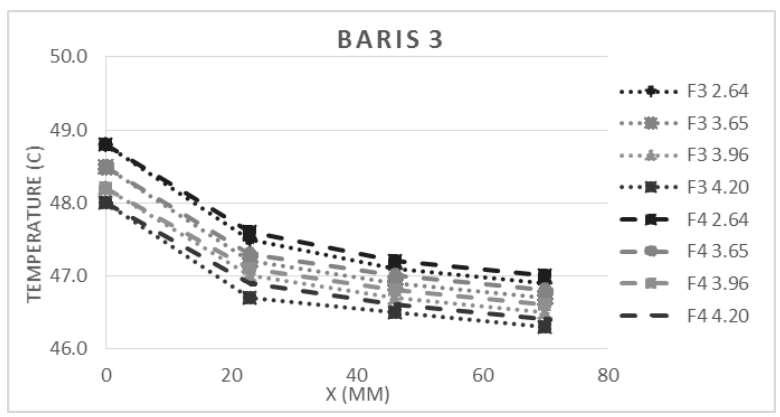

(a)

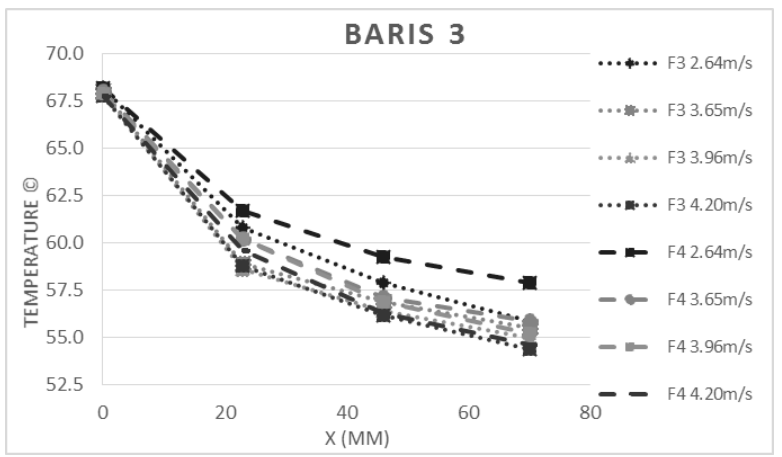

(b)

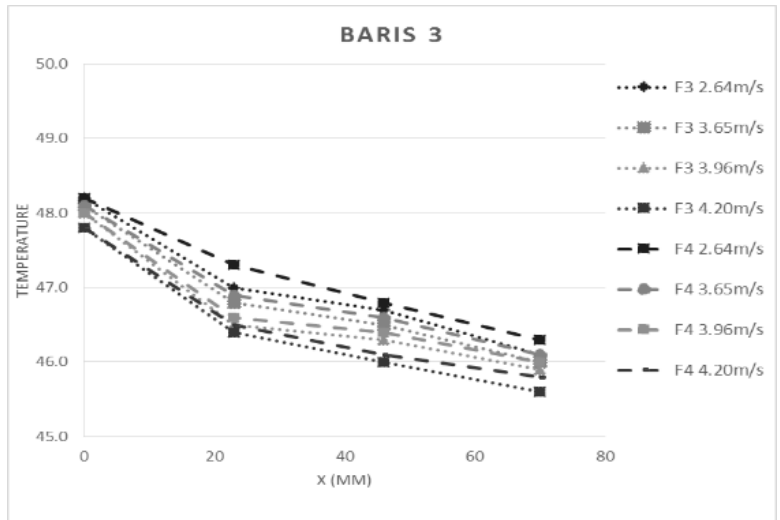

(c)

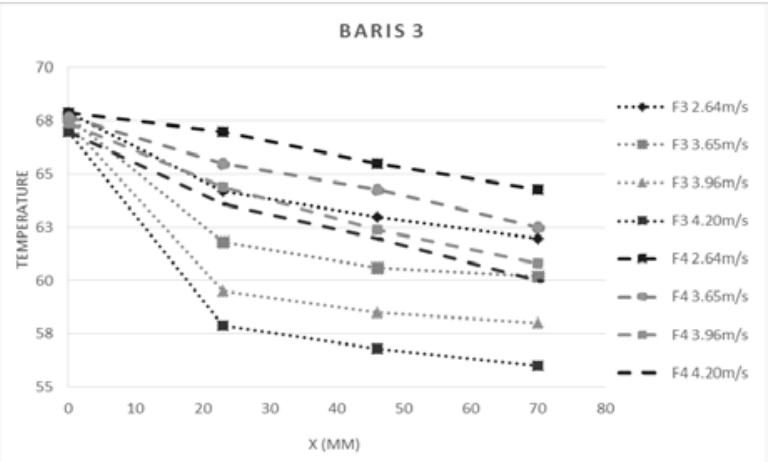

(d)

Gambar 8. Distribusi temperature pin fin pada baris ketiga (a) pin fin $10 \mathrm{~mm}$ set point $50^{\circ} \mathrm{C}$ (b) pin fin $10 \mathrm{~mm}$ set point $70^{\circ} \mathrm{C}$ (c) pin fin $16 \mathrm{~mm}$ set point $50^{\circ} \mathrm{C}$ (d) pin fin $16 \mathrm{~mm}$ set point $70^{\circ} \mathrm{C}$

Gambar 9 merupakan grafik distribusi temperature permukaan pin fin dengan diameter $10 \mathrm{~mm}$ dan $16 \mathrm{~mm}$ dengan set point $50^{\circ} \mathrm{C}$ dan $70^{\circ} \mathrm{C}$ pada baris keempat. Baris keempat terdiri dari 4 pin fin dengan 2 pin fin terukur yaitu pin fin 1 dan 2. Dari grafik dapat diketahui bahwa masing- 
masing pin fin mempunyai trendline grafik yang sama. Trendline grafik mengalami penurunan temperature di sepanjang pin fin. Temperature tertinggi terjadi pada $\mathrm{x}=0$ dan temperature terendah pada posisi $\mathrm{x}=70 \mathrm{~mm}$. Pin fin 1 memiliki temperature yang lebih tinggi daripada pin fin 2.

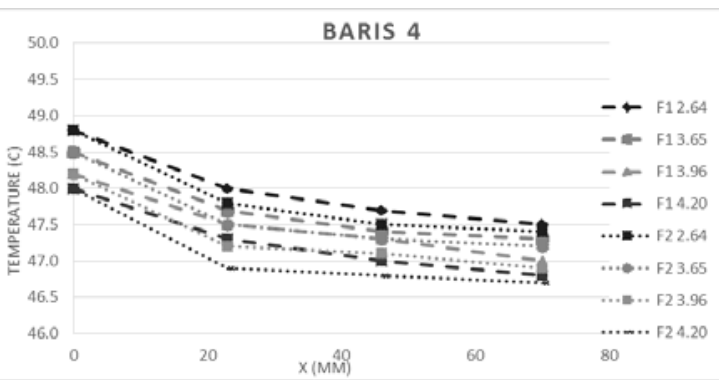

(a)

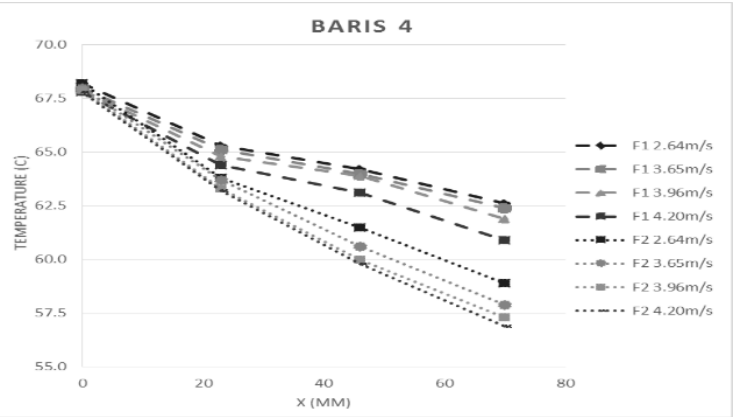

(b)

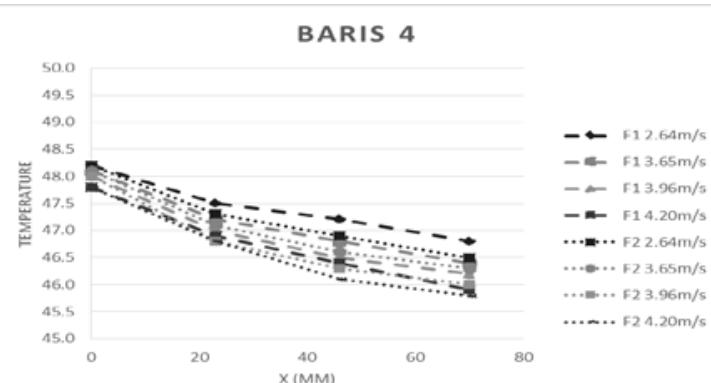

(c)

BARIS 4

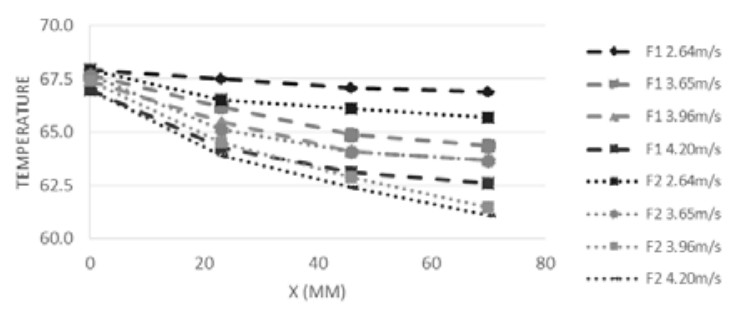

(d)

Gambar 9. Distribusi temperature pin fin pada baris keempat (a) pin fin 10 $\mathrm{mm}$ set point $50^{\circ} \mathrm{C}$ (b) pin fin $10 \mathrm{~mm}$ set point $70^{\circ} \mathrm{C}$ (c) pin fin $16 \mathrm{~mm}$ set point $50^{\circ} \mathrm{C}$ (d) pin fin $16 \mathrm{~mm}$ set point $70^{\circ} \mathrm{C}$

Masing-masing baris terdapat dua pin fin yang diukur temperaturenya, yakni pada sisi tepi dan pada sisi tengah. Pada pengukuran temperature pin fin sisi tengah hampir selalu lebih rendah daripada temperature pada sisi tepi dengan kecepatan yang sama. Hal ini dikarenakan pada pin fin sisi tepi memiliki kecepatan udara yang lebih rendah disebabkan adanya gesekan dengan dinding saluran. Kecepatan fluida yang lebih tinggi dapat membawa panas dari pin fin lebih besar dan menyebabkan terjadinya perpindahan panas yang lebih besar, sehingga pin fin di sisi tengah mempunyai temperature yang lebih rendah daripada sisi tepi.
Temperature permukaan fin paling tinggi terjadi pada kecepatan fluida sebsar $2.64 \mathrm{~m} / \mathrm{s}$, kemudian mengalami penurunan berturut-turut pada kecepatan $3.65 \mathrm{~m} / \mathrm{s}, 3.96 \mathrm{~m} / \mathrm{s}$ dan $4.20 \mathrm{~m} / \mathrm{s}$. Semakin besar kecepatan fluida yang mengalir melalui fin, maka semakin besar pula panas yang dapat terbawa oleh fluida tersebut, sehingga temperature pin fin menjadi lebih rendah.

B. Pengaruh Diameter Pin Fin dan Kecepatan Udara terhadap Perpindahan Panas Pin Fin

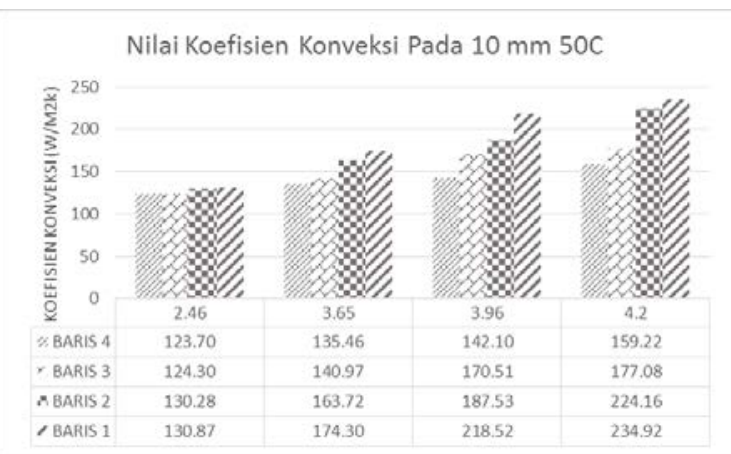

(a)

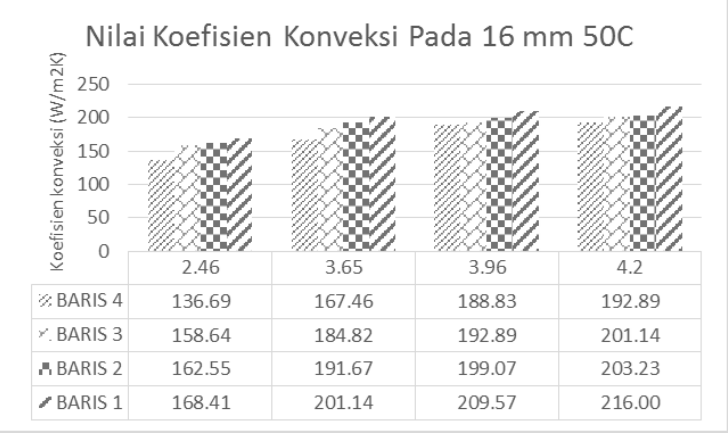

(b)

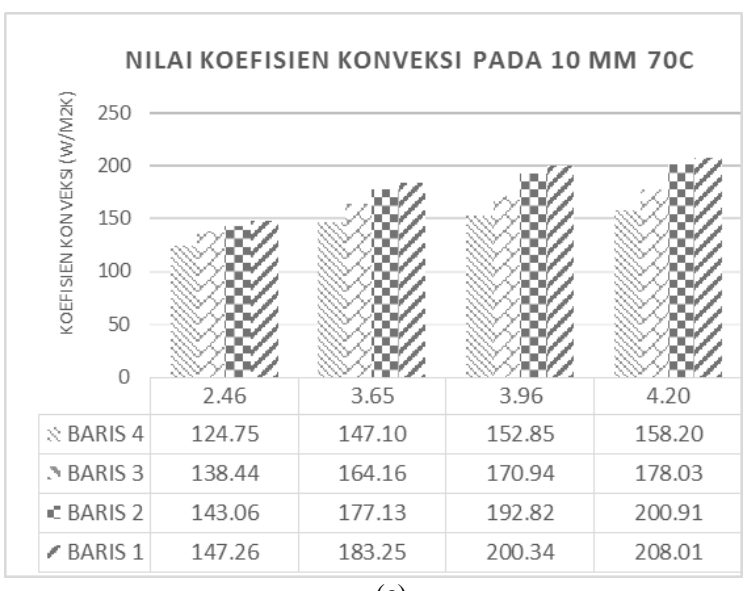

(c)

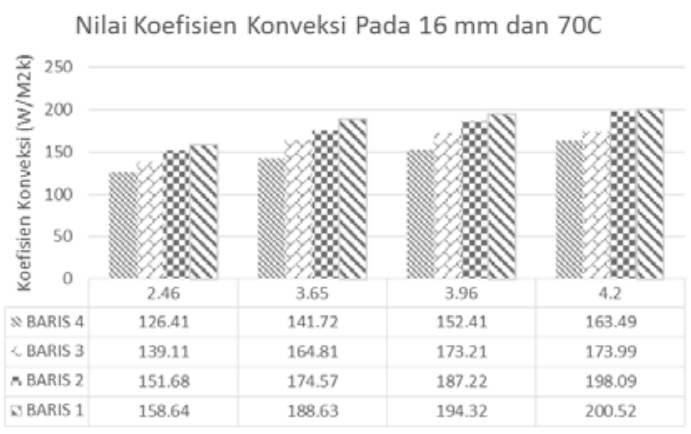

(d)

Gambar 10. Diagram nilai koefisien konveksi per baris (a) $10 \mathrm{~mm} 50^{\circ} \mathrm{C}$ (b) $16 \mathrm{~mm} 50^{\circ} \mathrm{C}$ (c) $10 \mathrm{~mm} 70^{\circ} \mathrm{C}$ (d) $16 \mathrm{~mm} 70^{\circ} \mathrm{C}$ 
Pada Gambar 10 merupakan diagram pengaruh diameter terhadap koefisien konveksi rata-rata di ssetiap baris pada setiap kecepatan fluida. Nilai koefisien konveksi tertinggi dicapai pada baris 1 atau baris pertama kali terkena aliran udara, sedangkan nilai koefisien konveksi terendah dicapai pada baris 4 atau baris yang terakhir terkena aliran udara. Interaksi perpindahan panas antar pin fin dapat mengakibatkan koefisien konveksi menjadi lebih rendah. Pin fin pada baris 1 merupakan pin fin yang berada pada posisi paling bawah atau yang pertama terkena aliran udara dalam susunan berkas sirip pin. Oleh karena itu, pin fin pada baris 1 tidak mendapatkan pengaruh perpindahan panas dari pin fin manapun, sehingga bisa didekati sebagai single cylinder pin fin. Sedangkan pada pin fin baris 2, 3 dan 4, memiliki nilai koefisien konveksi yang lebih rendah karena terkena pengaruh interaksi perpindahan panas dari pin fin sebelumnya. Berdasarkan eksperimen yang telah dilakukan, nilai koefisien konveksi tertinggi dicapai pada baris 1 untuk semua variasi diameter, set point dan kecepatan aliran udara. Hal ini dikarenakan, pin fin pada baris 1 tidak mendapat pengaruh interaksi dari pin fin sebelumnya atau bisa disebut sebagai single cylinder pin fin. Koefisien konveksi pada baris 4 memiliki nilai koefisien konveksi yang paling rendah dikarenakan adanya pengaruh interaksi dari pin fin sebelumnya.

Berdasarkan eksperimen yang telah dilakukan, nilai kecepatan fluida berpengaruh terhadap nilai Reynolds number. Reynolds number akan meningkat seiring bertambah besarnya kecepatan fluida. Selain itu, nilai Reynolds number memiliki pengaruh terhadap nilai Nusselt number, di mana Nusselt number merupakan fungsi dari Reynolds number, sehingga nilai Nusselt number meningkat seiring meningkatnya Reynolds number. Nilai Nusselt number yang semakin besar menyebabkan nilai koefisien konveksi ratarata semakin meningkat.

Untuk diameter yang lebih kecil, nilai koefisien konveksi rata-rata lebih besar daripada diameter yang lebih besar. Hal ini dikarenakan, pada diameter $10 \mathrm{~mm}$, pitch atau spasi antar pin fin semakin besar sehingga menyebabkan interaksi perpindahan panas antar pin fin menjadi berkurang, akibatnya perpindahan panas yang terjadi lebih besar yang ditunjukkan dengan nilai koefisien konveksi yang lebih besar.

C. Pengaruh Diameter dan Bilangan Reynolds terhadap Koefisien Konveksi Rata-rata Pada Set Point $50^{\circ} \mathrm{C}$ dan $70^{\circ} \mathrm{C}$

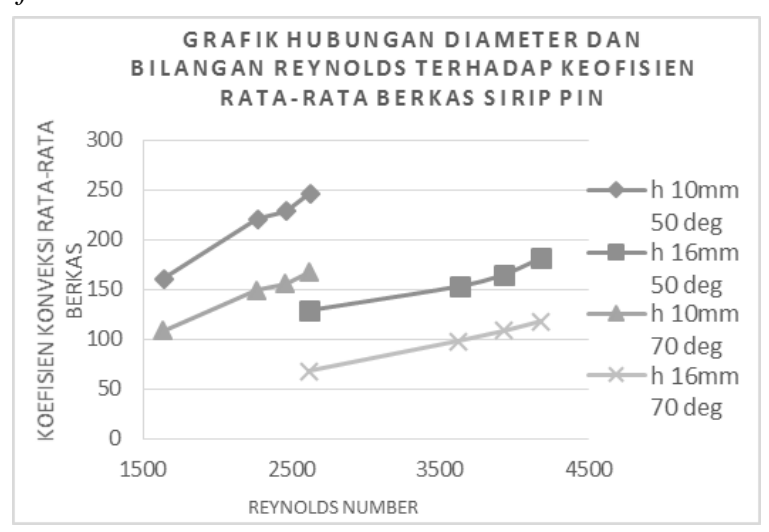

Gambar 11. Grafik hubungan diameter dan bilangan Reynolds terhadap koefisien konveksi pada set point $50^{\circ} \mathrm{C}$ dan $70^{\circ} \mathrm{C}$

Berdasarkan eksperimen yang telah dilakukan, nilai kecepatan fluida berpengaruh terhadap nilai Reynolds number. Reynolds number akan meningkat seiring bertambah besarnya kecepatan fluida. Selain itu, nilai Reynolds number memiliki pengaruh terhadap nilai Nusselt number, di mana
Nusselt number merupakan fungsi dari Reynolds number, sehingga nilai Nusselt number meningkat seiring meningkatnya Reynolds number. Untuk diameter yang lebih kecil, nilai koefisien konveksi rata-rata lebih besar daripada diameter yang lebih besar. Hal ini dikarenakan, pada diameter $10 \mathrm{~mm}$, pitch atau spasi antar pin fin semakin besar sehingga menyebabkan interaksi perpindahan panas antar pin fin menjadi berkurang, akibatnya perpindahan panas yang terjadi lebih besar yang ditunjukkan dengan nilai koefisien konveksi yang lebih besar. Pin fin dengan kecepatan dan diameter yang sama, pin fin dengan set point $50^{\circ} \mathrm{C}$ mempunyai nilai koefisien konveksi yang lebih tinggi dari pada pin fin dengan set point $70^{\circ} \mathrm{C}$. Nilai koefisien konveksi ini dipengaruhi oleh aliran fluida yang membawa panas. Pada kecepatan yang sama, saat diterapkan untuk set point yang tinggi, panas yang terbawa oleh fluida semakin kecil, sehingga penurunan temperature menjadi kecil. Ketika diterapkan pada set point yang lebih rendah, panas yang terbuang dan terbawa oleh fluida semakin besar sehingga penurunan temperatur lebih besar. Hal ini menyebabkan, berkas pin fin dengan set point $50^{\circ} \mathrm{C}$ mempunyai koefisien konveksi yang lebih baik dari pada dengan set point $70^{\circ} \mathrm{C}$

\section{KESIMPULAN DAN SARAN}

Pada kecepatan yang sama, pin fin diameter $10 \mathrm{~mm}$ mempunyai koefisien konveksi yang lebih besar daripada pin fin diameter $16 \mathrm{~mm}$ untuk set point yang sama.

Semakin besar Reynolds number, maka semakin tinggi pula koefisien konveksi yang terjadi.

Nilai koefisien konveksi paling tinggi dicapai pada baris pertama yang terkena aliran udara dan nilai koefisien konveksi paling rendah dicapai pada baris terakhir yang terkena aliran udara

Distribusi temperature pin fin menurun di sepanjang pin fin. Temperature permukaan pin fin tertinggi dicapai oleh pin fin pada baris keempat atau baris terakhir yang terkena aliran udara. Pin fin yang terletak di sebelah tepi mempunyai temperature yang lebih tinggi daripada pin fin di tengah.

\section{LAMPIRAN}

$A, A_{s}$ luas permukaan, $\mathrm{m}^{2}$

$A_{c} \quad$ luas penampang, $\mathrm{m}^{2}$

$A_{f f}$ free flow area, $\mathrm{m}^{2}$

$A_{t} \quad$ luas permukaan total, $\mathrm{m}^{2}$

$c_{p} \quad$ panas jenis udara, J/kg.K

$h \quad$ koefisien perpindahan panas konveksi, $W / m 2 K$

$k \quad$ konduktivitas termal, $\mathrm{W} / \mathrm{mK}$

$L \quad$ panjang, $m$

Lc panjang karakteristik, $m$

$\dot{m} \quad$ laju aliran massa udara, $\mathrm{kg} / \mathrm{s}$

$\mathrm{Nu}$ bilangan Nusselt

$q \quad$ laju perpindahan panas, $W$

af laju perpindahan panas pada fin, $W$

qt laju perpindahan panas total, $W$

Re bilangan Reynolds

Rt,c thermal contact resistance, $K / W$

$R t, f$ fin thermal resistance, $K / W$

$R t, o$ thermal resistance of fin array, K/W

$S D$ diagonal pitch, $m$

SL longitudinal pitch, $m$

ST transversal pitch, $m$ 
$T$ temperature, $K$

$t \quad$ thickness, $m$

$V$ kecepatan, $\mathrm{m} / \mathrm{s}$

$w \quad$ lebar, $m$

$\theta \quad$ distribusi temperatur, $K$

\section{DAFTAR PUSTAKA}

[1] A. Eldhose, B. Paul, and J. T. Sebastian, "Numerical analysis of pin fin by varying shape and materials,” Int. Res. J. Eng. Technol., vol. 5, no. 4, pp. 2750-2755, 2018.

[2] T. Istanto and W. E. Juwana, "Karakteristik perpindahan panas dan penurunan tekanan sirip-sirip pin silinder tirus susunan segaris dan selang-seling dalam saluran segi empat,” J. Tek. Mesin, vol. 12, no. 1, pp. 58-64, Dec. 2010. 